\title{
Article \\ Comparison of Tar Samples from Reaction Zone and Outlet in Ex-Situ Underground Coal Gasification Experiment
}

\author{
Lele Feng ${ }^{1,2, * \mathbb{C}}$, Maifan Dong ${ }^{1}$, Yuxin $\mathrm{Wu}^{3}$ and Junping $\mathrm{Gu}{ }^{4}$ \\ 1 School of Safety Engineering, China University of Mining and Technology, Xuzhou 221116, China; \\ 18811709095@163.com \\ 2 Key Laboratory of Deep Earth Science and Engineering (Sichuan University), Ministry of Education, \\ Chengdu 610065, China \\ 3 Key Laboratory for Thermal Science and Power Engineering of Ministry of Education, Department of Energy \\ and Power Engineering, Tsinghua University, Beijing 100084, China; wuyx09@tsinghua.edu.cn \\ 4 Qian Xuesen Laboratory of Space Technology, China Academy of Space Technology, Beijing 100094, China; \\ gjp_thu@163.com \\ * Correspondence: fenglele@cumt.edu.cn; Tel.: +86-516-83995097
}

check for

updates

Citation: Feng, L.; Dong, M.; Wu, Y.; Gu, J. Comparison of Tar Samples from Reaction Zone and Outlet in Ex-Situ Underground Coal Gasification Experiment. Energies 2021, 14, 8570. https://doi.org/ $10.3390 /$ en14248570

\section{Academic Editors: Manoj}

Khandelwal and Pathegama

Gamage Ranjith

Received: 18 November 2021

Accepted: 16 December 2021

Published: 19 December 2021

Publisher's Note: MDPI stays neutral with regard to jurisdictional claims in published maps and institutional affiliations.

Copyright: (c) 2021 by the authors. Licensee MDPI, Basel, Switzerland. This article is an open access article distributed under the terms and conditions of the Creative Commons Attribution (CC BY) license (https:/ / creativecommons.org/licenses/by/ $4.0 /)$.

\begin{abstract}
Tar remaining in the gasification cavity during underground coal gasification (UCG) is an important pollution source, while the reported studies only focus on the tar behavior at the outlet. The present work aims to compare the tar properties from the reaction zone and the outlet, analyze the tar evolution during gasification, and discuss possible measures to control tar pollution. Tar was sampled with a self-developed equipment from an ex-situ underground coal gasification experimental system and analyzed by GC-MS. The gas composition, temperature, and PM10 were also compared for the reaction zone and the outlet. Compared with the tar from reaction zone, the tar from outlet has a smaller percentage of high boiling point content, $\mathrm{PAHs}, \mathrm{C}, \mathrm{O}, \mathrm{N}, \mathrm{S}, \mathrm{Cl}, \mathrm{Si}$, and a larger percentage of $\mathrm{H}$. The PAHs percentage in tar at the outlet in this work is closer to the field data than the lab data from literature, indicating the experimental system gives a good simulation of tar behavior in underground coal gasification. Condensation due to a fast temperature drop is one of the main reasons for PAHs decreasing. Tar cracking and soot formation also cause the decrease of heavy tar, proven by the light gas and particulate matter results.
\end{abstract}

Keywords: underground coal gasification; tar; ex-situ experiment

\section{Introduction}

Underground coal gasification (UCG) is a technology which transforms the in-situ coal seam into combustible gas with high calorific value without coal mining activities [1-3]. Underground coal gasification is regarded as an effective method for the development and utilization of deep coal resources, with the characteristics of clean utilization, technical feasibility, and economic efficiency $[4,5]$. There are more than 36 field testing sites for underground gasification in over 10 countries-such as the USA, Australia, and Chinawhile only a few projects are continuously operating [6,7]. In China, more than $70 \%$ of the proven reserves of coal are distributed deeper than $2000 \mathrm{~m}$, while the state-of-art mining technology only works for a maximum depth of $1500 \mathrm{~m}$. Thus it is important to develop the underground coal gasification technology, especially for the deep coal resources. One of the main challenges for utilization of underground coal gasification technology is the pollution problem [8,9], such as tar remaining in the gasification cavity.

Many researchers have carried out experimental studies on tar behaviors in UCG, including lab test [10-14] and field test [15-20]. Kumari et al. [10,11] studied the $\mathrm{CO}_{2}$ dry reforming of tar through lab-scale ex-situ experiment, and found the catalytic effect of coal char on the tar conversion to light gas, which offers a new method to improve the product gas quality. Xu et al. [12] found a decrease of tar yields as the pyrolysis temperature 
increases, based on a high temperature tube furnace under UCG conditions. Mandal et al. [13] uses FTIR method to study the chemical bonds and molecular structure of tar from lab UCG experiment. Researchers from the Central Mining Institute (Poland) [14] studied the environmental risk of the waste water in lab tests, and found high toxicity from both organic and inorganic content in the waste water. Zhou et al. [15] investigated the effect of pyrolysis temperature, operating pressure, water influx, and gasification agent injection on the production, viscosity, and compound content of tar from UCG trial at Inner Mongolia, China. Wiatowski et al. [16-18] carried out a series of inspiring work on the tar properties from the UCG trial in the "Wieczorek" mine in Poland. The element composition, heating value, molar mass, and other properties of tar samples were analyzed and compared comprehensively. Grabowski et al. [19] monitored the water quality near a UCG trial after 6-month gasification test, and analyzed the tar properties condensed in the gas processing system. Mallett et al. [20] studied the water sample from UCG field test in Queensland, Australia, found that in-flow groundwater could help retain the pollutants in the cavity, while out-flow groundwater causes a fast migration of the pollutants—such as benzene.

Some researchers use numerical simulation methods to study the tar yields in UCG. Klebingat et al. [21] established a process model for prediction of gas quality and tar production. The simulated tar yields and composition agree well with the literature results. This model was further used to optimize the operating parameters in UCG [22]. Soukup et al. [23] developed a porous media model to simulate the migration of pollutants such as benzene, and further evaluated the effects of pore size, porosity, tortuosity, and reaction conditions on the migration rate.

Even though there are many interesting and inspiring reported studies on tar in UCG, there are several problems remained to be solved. Firstly, it is well known that the tar properties at the outlet of lab UCG test are far different from those of field test [24], which limits the application of some results found in labs. Secondly, all the reported studies-no matter experiments or simulations-only focus on the tar behavior at outlet of gasifier, which follows the investigation logic of traditional gasifier on the ground. However, the tar remained in the gasification cavity of UCG is a more important pollution source, which is difficult to collect and deal with. Meanwhile, tar yields and evolution are closely related to the carbon conversion, and the condensed tar may cause pipe blockage at the gasifier outlet. Thus, it is necessary to study the tar behavior in the gasification channel, rather than only at the outlet.

In this work, an ex-situ underground coal gasification experimental system was built, and Shenmu bituminous coal is used as the gasification raw material. A sampling method was proposed to compare the tar behaviors from the reaction zone and the outlet. The differences of tar samples in boiling point, compound content, and element composition were studied and discussed in detail.

\section{Materials and Methods}

\subsection{Underground Gasification Experimental System}

The ex-situ underground gasification experimental system is mainly composed of gas supply unit, gasification reaction unit, sampling unit and gas analysis unit, as shown in Figure 1. The gasification reaction unit consists of reactor, refractory brick, and coal block. In particular, the coal block is composed of four small blocks, each with a size of $230 \times 230 \times 115 \mathrm{~mm}$, and there is a borehole with a size of $10 \times 5 \mathrm{~mm}$ on one side of the block surface. After combining 4 small blocks, the final size is $460 \times 230 \times 230 \mathrm{~mm}$, with a borehole of $10 \times 10 \mathrm{~mm}$ as the initial gasification channel. Two layers of refractory bricks are surrounded outside the coal, and the thickness of single layer of refractory brick is $70 \mathrm{~mm}$. The refractory brick and coal block are placed in the steel square reactor. The inlet and outlet gas pipes are mounted on the left and right sides of the reactor respectively, with a diameter of $6 \mathrm{~mm}$. Five pipes are set at both the upper and the lower walls of the reactor, reserved for temperature measuring wires and a sampling system. 


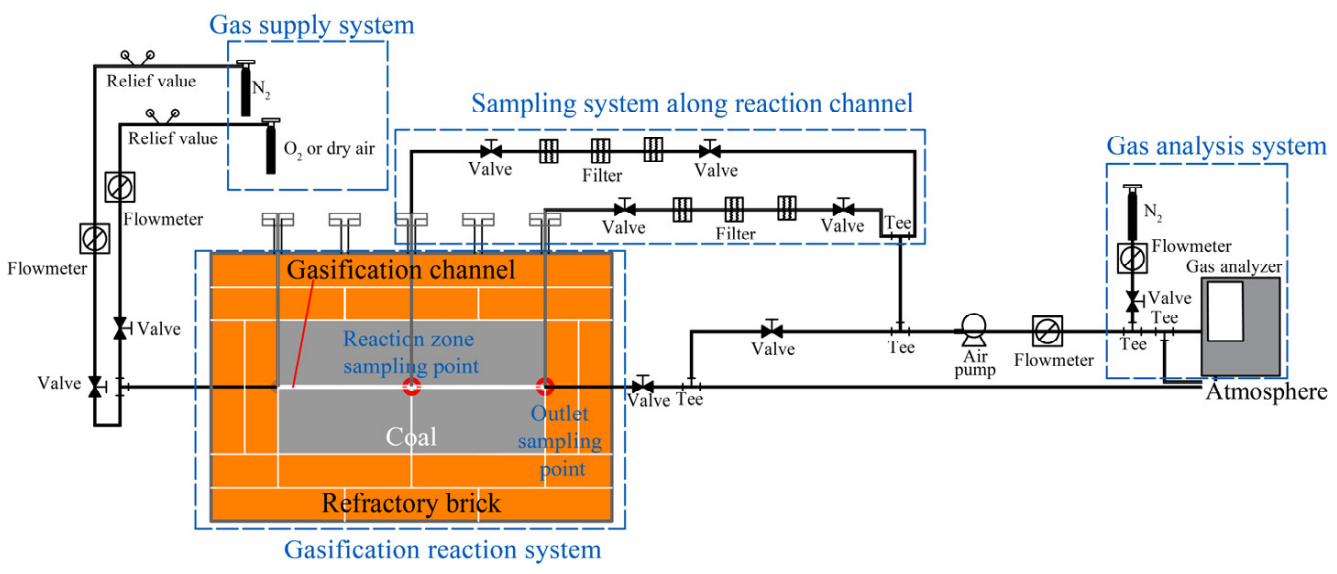

Figure 1. Schematic diagram of underground gasification experimental system.

The gas analysis unit consists of dilution gas circuit and gas analyzer. Since pure oxygen is used as gasification agent in the experiment, the direct measurement of oxygen content may exceed the range of gas analyzer, so dilution pre-processing method is adopted to ensure that the measured value is within the range.

\subsection{Tar Sample Collection}

Tar samples are collected by the sampling unit, composed of a sampling pipe, valve, filter, flowmeter, and vacuum pump. The front end of the sampling pipe extends vertically into the initial gasification channel. Since the ignition position in the experiment is at the center of the coal block in the gasification channel, for this work we selected the ignition position for tar sampling as the 'reaction zone', and chose the end of the gasification channel as another sampling point (the 'outlet'), shown in Figure 1. The sampling gas flow is controlled to $0.2 \mathrm{~L} / \mathrm{min}$ through the vacuum pump and valve, and the tar is captured through the multi-stage filter.

\subsection{Tar Sample Analysis}

The collected tar mixture is dissolved in dichloromethane, and then treated by ultrasonic oscillation and centrifuge respectively to obtain upper liquid and lower liquid. The dichloromethane solution of tar can be obtained after filtering the lower liquid many times, and then the chemical components of tar can be analyzed by gas chromatographymass spectrometry (GC-MS). The collected tar samples were analyzed by red hot gas chromatography-mass spectrometry produced by Perkin Elmer Company, the United States. The measured molecular weight is $1 \sim 1200 \mathrm{amu}$, and the injection volume is 0.03 $\mu \mathrm{L}$ with nitrogen as carrier gas. The initial temperature is $40^{\circ} \mathrm{C}$, while after $3 \mathrm{~min}$ it rises to $100{ }^{\circ} \mathrm{C}$ at $4{ }^{\circ} \mathrm{C} / \mathrm{min}$. Then the temperature keeps constant for $3 \mathrm{~min}$, and finally it rises to $240{ }^{\circ} \mathrm{C}$ at $6^{\circ} \mathrm{C} / \mathrm{min}$ and keeps constant for $10 \mathrm{~min}$. The mass spectrometer detector adopts full scanning mode.

\subsection{Experimental Conditions}

The coal sample used in the experiment is Shaanxi Shenmu bituminous coal, and the industrial analysis results are shown in Table 1. The gasification agent used in the experiment was pure oxygen, the flow rate was $8 \mathrm{~L} / \mathrm{min}$, and the gasification reaction time was $4 \mathrm{~h}$.

Table 1. Coal industry analysis.

\begin{tabular}{cccc}
\hline Moisture $\left(\mathbf{M}_{\mathrm{ad}}\right)$ & Ash Content $\left(\mathbf{A}_{\mathbf{a d}}\right)$ & Volatile Matter $\left(\mathbf{V}_{\mathrm{ad}}\right)$ & Fixed Carbon $\left(\mathrm{FC}_{\mathrm{ad}}\right)$ \\
\hline 14.22 & 6.45 & 24.44 & 54.89 \\
\hline
\end{tabular}




\section{Results}

\subsection{Tar Sample Analysis}

\subsubsection{Content and Properties}

Over 100 kinds of compounds were detected in the tar samples by GC-MS. Table 2 shows only the top 10 contents in the tar samples from the reaction zone and the outlet. Polycyclic aromatic hydrocarbons (PAHs) account for the largest proportion in tar, followed by benzene and its derivatives (BTX) and phenolic compounds. Naphthalene has the largest mass percentage in both tar samples, with $8.9 \%$ for reaction zone sample and $15.3 \%$ for outlet sample.

Table 2. Top 10 contents in the tar samples.

\begin{tabular}{|c|c|c|c|}
\hline \multicolumn{2}{|c|}{ Reaction Zone } & \multicolumn{2}{|l|}{ Outlet } \\
\hline Name & Percentage & Name & Percentage \\
\hline Naphthalene & $8.9 \%$ & Naphthalene & $15.3 \%$ \\
\hline Pyrene & $6.2 \%$ & 1-Methylnaphthalene & $15.2 \%$ \\
\hline 1-Methylnaphthalene & $5.8 \%$ & Toluene & $14.7 \%$ \\
\hline Fluorene & $5.3 \%$ & 3-Ethynyltoluene & $7.8 \%$ \\
\hline Phenanthrene & $4.4 \%$ & 2-Methylnaphthalene & $5.5 \%$ \\
\hline Acenaphthylene & $4.3 \%$ & 2,2'-Methylenebis(6-tert-butyl-4-Methylphenol) & $4.9 \%$ \\
\hline Benzo(c)fluorene & $4.0 \%$ & 1-Hydroxycyclohexyl phenyl ketone & $3.9 \%$ \\
\hline 2-Methylanthracene & $3.6 \%$ & M-Xylene & $3.5 \%$ \\
\hline P-Cresol & $2.8 \%$ & Styrene & $2.5 \%$ \\
\hline 1,7-Dimethylnaphthalene & $2.8 \%$ & 3,5-di-tert-butylphenol & $1.7 \%$ \\
\hline
\end{tabular}

According to the detected tar contents, the mass percentage of compounds with different boiling points were determined, as shown in Figure 2. For tar sample from reaction zone, $9.9 \%$ of the compounds in tar have a boiling point between 100 and $200{ }^{\circ} \mathrm{C}$, $49.2 \%$ between 200 and $300{ }^{\circ} \mathrm{C}$, and $39.2 \%$ over $300{ }^{\circ} \mathrm{C}$. For tar sample from outlet, $33 \%$ of the compounds in tar have a boiling point between 100 and $200{ }^{\circ} \mathrm{C}, 48.7 \%$ between 200 and $300{ }^{\circ} \mathrm{C}$, and $13.9 \%$ over $300^{\circ} \mathrm{C}$. Compared to the reaction zone sample, the contents with high boiling points in the outlet sample are apparently lower, indicating either chemical consumption or physical condensation of heavy tar.

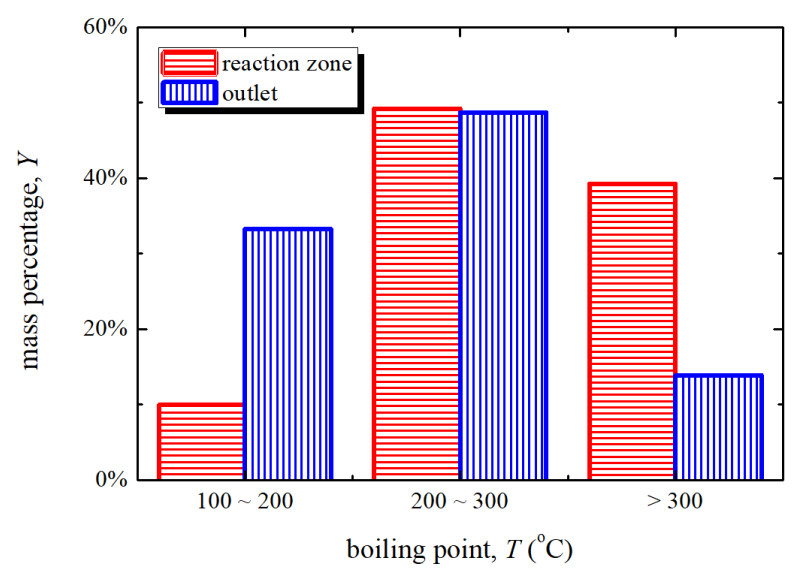

Figure 2. Percentage of compounds with different boiling points.

Furthermore, the compounds in tar are classified by the number of aromatic rings, as shown in Figure 3. For tar samples from the reaction zone, compounds with 2 aromatic rings are the major content, with a percentage of $42.9 \%$, followed by compounds with 3 rings, 1 ring, 4 rings, and 0 rings. While for the outlet sample, compounds with 3 or 4 rings are not found. Instead, the percentages of 0-ring and 1-ring compounds are obviously higher than those in the reaction zone. The results further demonstrate a decrease of heavy 
tar content. According to Figures 2 and 3, the tar properties from the reaction zone and the outlet are apparently different, and it is not enough to focus only on the tar behavior in the product gas. For the traditional gasifier on the ground, tar remaining in the reactor could be collected easily, while for underground gasification it is very difficult. Thus, it is suggested to adjust the temperature distribution in the underground gasification channel to control the yields and condensation of tar.

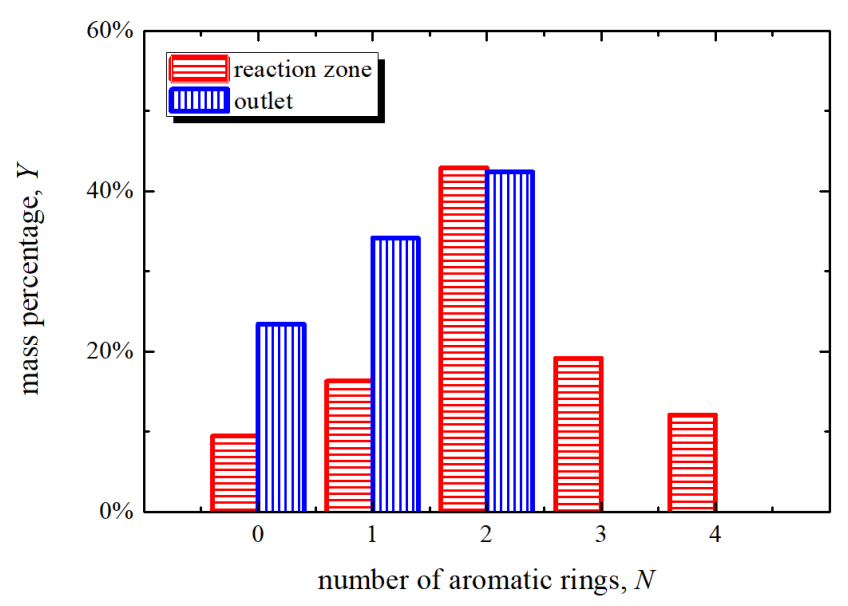

Figure 3. Percentage of compounds with different numbers of aromatic rings.

The elemental composition of tar samples are compared, as shown in Figure 4. For the reaction zone sample, $\mathrm{C}$ has the largest molar percentage of $50.4 \%$, followed by $\mathrm{H}$ of $47.0 \%$. While for outlet sample, molar percentages of $\mathrm{C}$ and $\mathrm{H}$ are $44.2 \%$ and $54.1 \%$, respectively, leading to a $\mathrm{H} / \mathrm{C}$ ratio larger than unity. This indicates a decrease of unsaturated compounds from the reaction zone to outlet. For both tar samples, $\mathrm{C}$ and $\mathrm{H}$ are the major contents, while all other elements are less than $2 \%$. Compared with reaction zone sample, $\mathrm{O}, \mathrm{N}, \mathrm{S}, \mathrm{Cl}$, and $\mathrm{Si}$ are less in outlet sample, indicating a potential pollution problem by $\mathrm{N}, \mathrm{S}$, and $\mathrm{Cl}$ in either the product gas or the gasified coal seam during underground coal gasification.

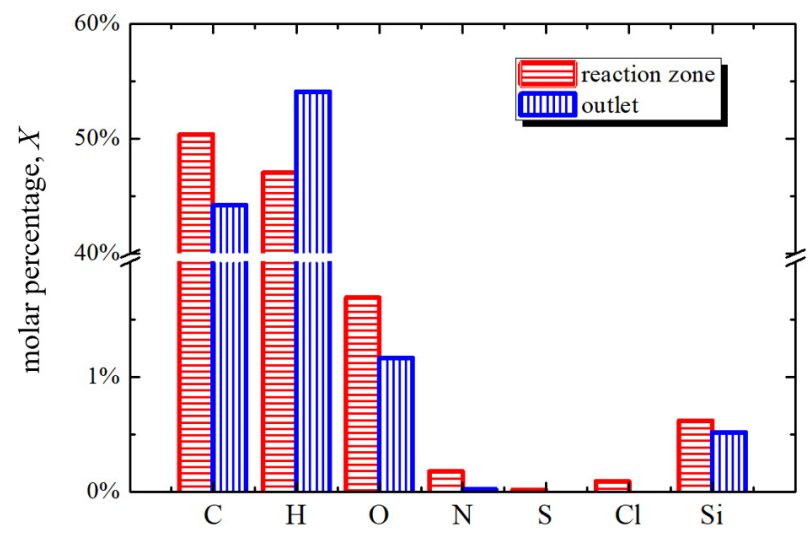

Figure 4. Elemental composition of tar samples.

\subsubsection{Comparison with Literature}

The percentage of PAHs in tar in this work was compared with the ex-situ and in-situ experimental results from other studies $[18,24,25]$. It is shown in Figure 5 that the heavy tar in the outlet of field test is less than that in lab test, which might be caused by the low outlet temperature for in-situ case. Apparently, the lab data in this work is closer to the field data than the lab data from Wang [25] and Liu [24]. The outlet temperature is relatively low in this work since the reactor is much bigger than the coal block, leading to a large heat loss around the gasification channel, which is close to the situation underground. Therefore, 
the experimental system gives a good simulation of tar behavior in underground coal gasification.

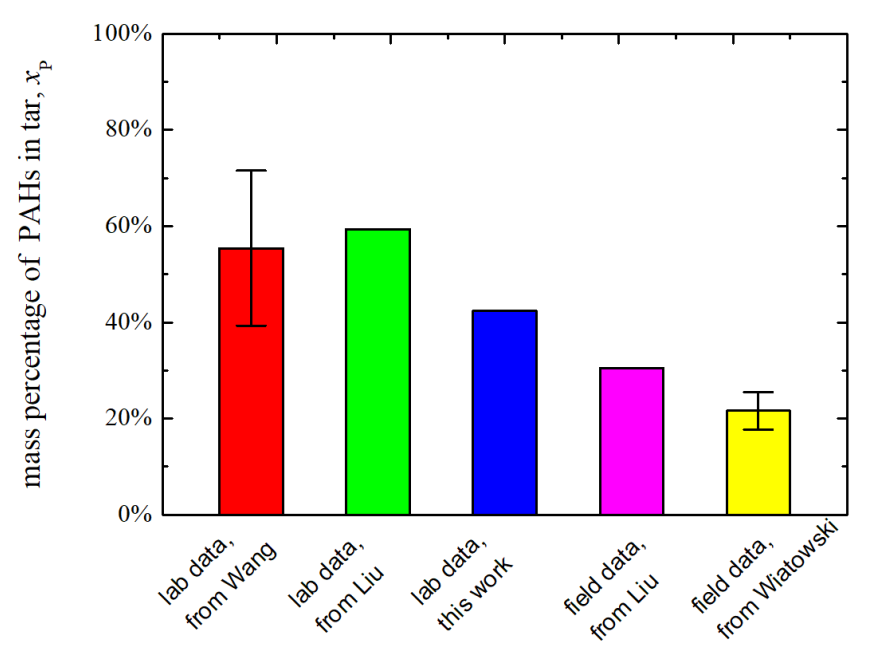

Figure 5. Comparison of PAHs in tar from outlet with literatures.

\subsection{Tar-Related Results}

\subsubsection{Temperature}

Figure 6 shows the measured temperature during gasification experiment. According to Figure $6 \mathrm{a}$, the temperature at reaction zone is between $800^{\circ} \mathrm{C}$ and $1200^{\circ} \mathrm{C}$ for most of the time, while sometimes higher than the permitted value of K-type thermocouple $\left(1300^{\circ} \mathrm{C}\right)$. The outlet temperature is between $20^{\circ} \mathrm{C}$ and $40^{\circ} \mathrm{C}$, barely changing with the gasification process. Figure $6 \mathrm{~b}$ shows the temperature field at $t=100 \mathrm{~min}$, based on the interpolation and measured data from 15 thermocouples. The flow direction is from the left to the right. It is shown that the reaction region expands both upwards and downwards, while the expanding distance downwards is longer. The position of the maximum temperature is at the upper left of the marked reaction zone (center of the block), caused by the buoyancy effect and the transport of oxygen. The temperature gradient from reaction zone to outlet is $3000-5000{ }^{\circ} \mathrm{C} / \mathrm{m}$, indicating severe condensation of heavy tar in the gasification channel.

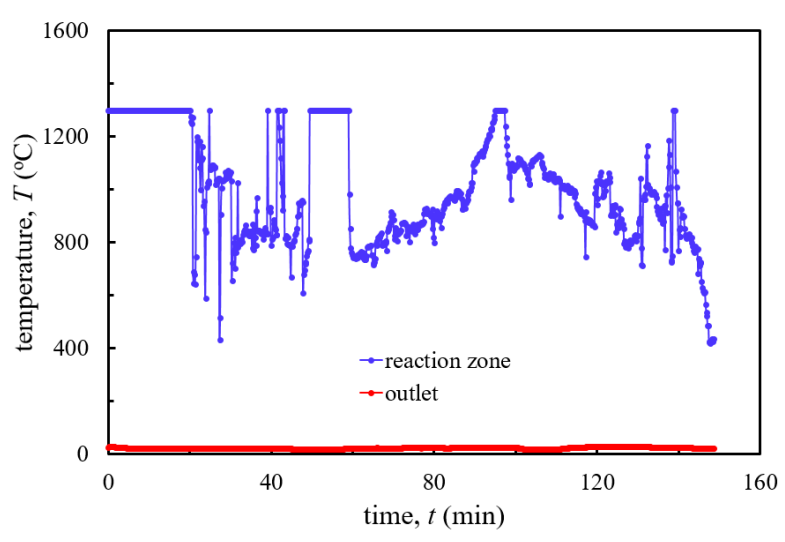

(a)

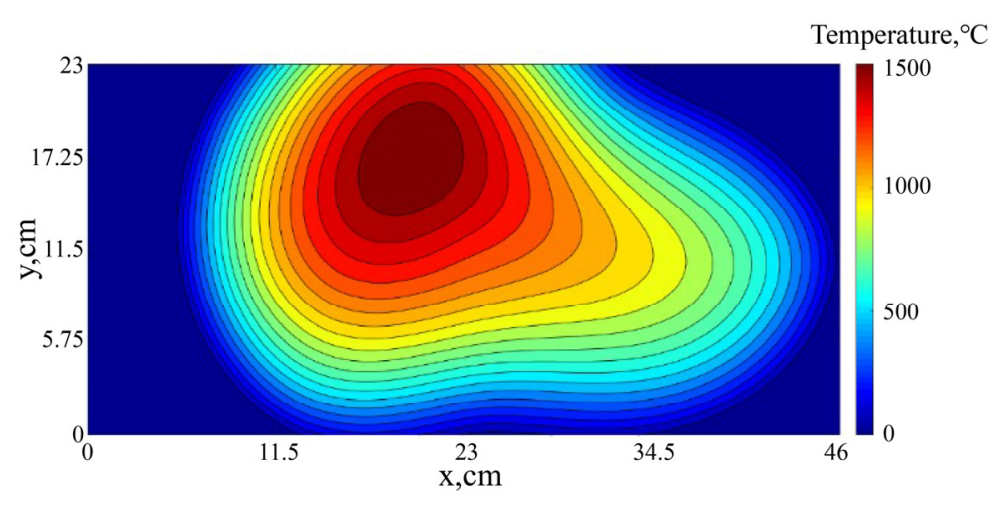

(b)

Figure 6. (a) Temperature variation of reaction zone and outlet; (b) Temperature field at $t=100 \mathrm{~min}$.

\subsubsection{Gas Composition}

The measured gas compositions from the reaction zone and outlet are shown in Figure 7. When $t<100 \mathrm{~min}, \mathrm{CO}$ is the major content in the gas mixture, indicating that gasification dominates; while when $t>100 \mathrm{~min}, \mathrm{CO}_{2}$ is the major content, which means that combustion dominates. As the coal consumption increases, the reaction creates oxygen-rich 
conditions, so yields of $\mathrm{CO}_{2}$ are greater than $\mathrm{CO}$. For the gasification stage, the percentages of $\mathrm{CO}, \mathrm{H}_{2}$, and $\mathrm{CO}_{2}$ in outlet gas are a little higher than those in reaction zone gas, which might be caused by the tar cracking or reforming.

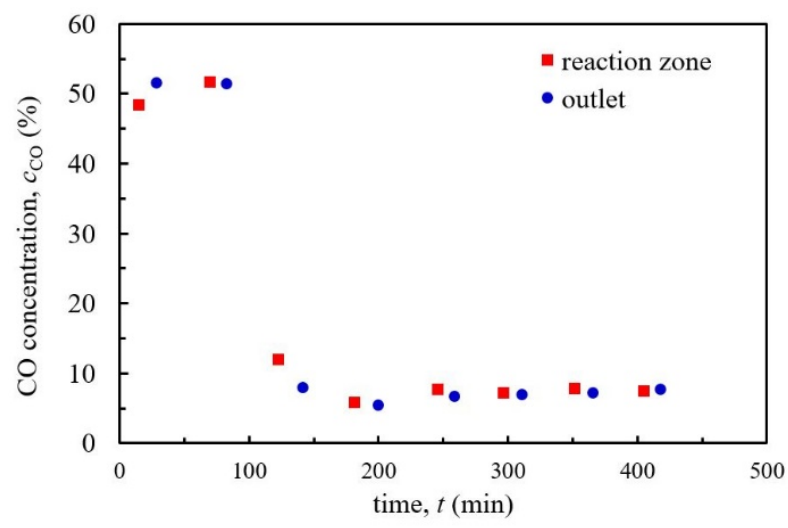

(a)

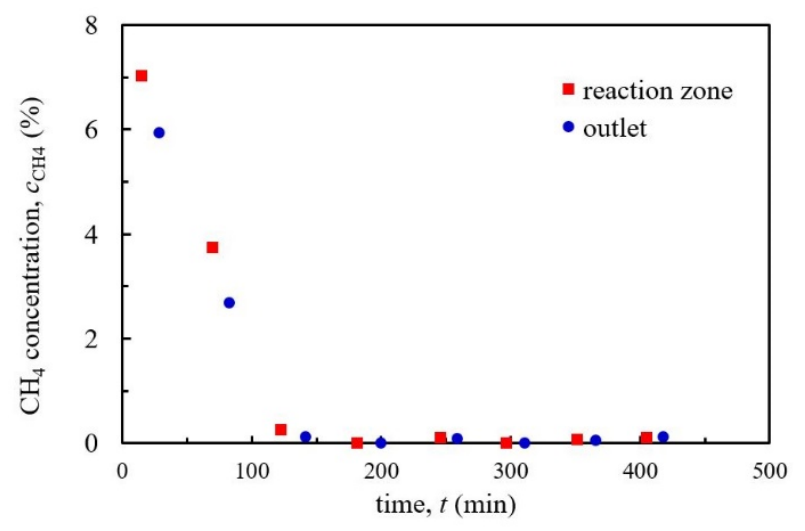

(c)

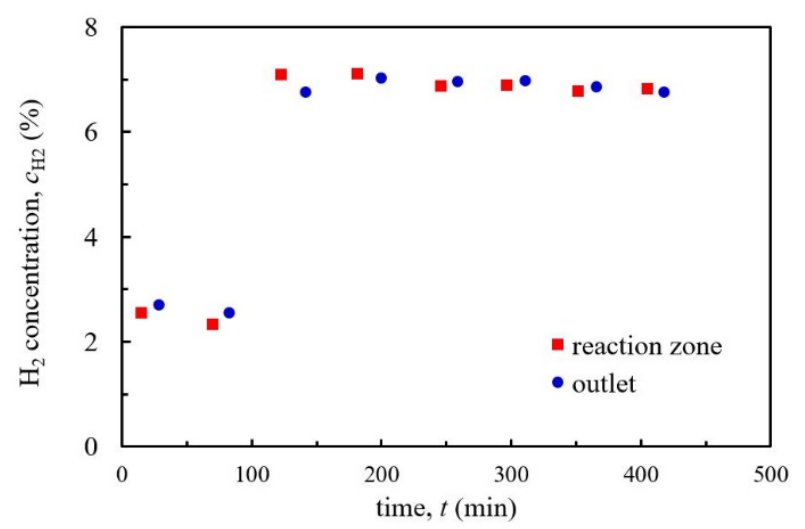

(b)

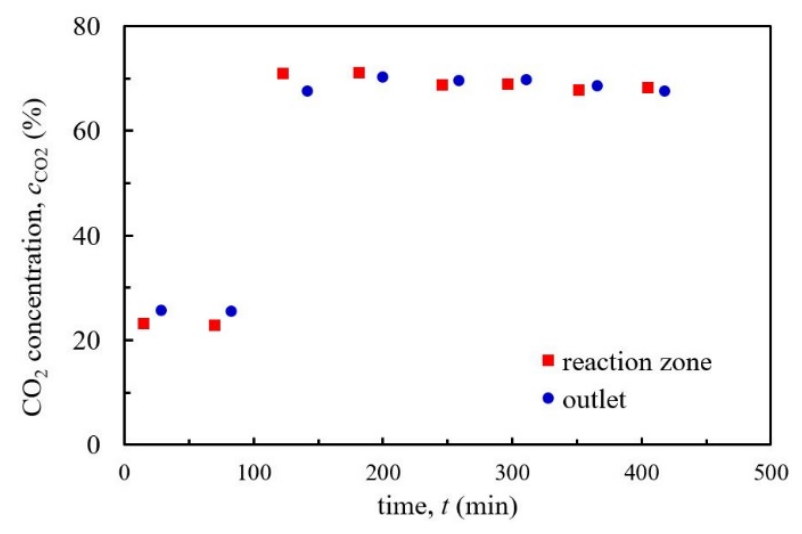

(d)

Figure 7. Gas composition of (a) $\mathrm{CO}$; (b) $\mathrm{H}_{2} ;$ (c) $\mathrm{CH}_{4}$; (d) $\mathrm{CO}_{2}$.

\subsubsection{PM10}

The particulate matter behavior is also a widely concerned issue in coal combustion and gasification. Figure 8 shows the diameter distribution and sphericity of the collected particle samples from the reaction zone and outlet. According to Figure 8a, the particle size at outlet is larger than that at the reaction zone. According to Figure 8b, there are two differences between the two particle samples. Firstly, fine particles smaller than $5 \mu \mathrm{m}$ are not found at the outlet. Secondly, the particle shape at the outlet is closer to a sphere. The fine particles follow the gas flow well, thus it is not possible to settle down in the gasification channel, which means the fine particles experience either agglomeration or oxidization reactions. However, the agglomerates of fine particles-such as soot clusters-usually features with branched or long-chain configurations, different from the near spherical particles at outlet. Therefore, it is inferred that the fine particle oxidization takes place from the reaction zone to the outlet. It is known that tar cracking and oxidization is faster than fine particle oxidization [26], thus the chemical consumption might be another reason for the decrease of heavy tar in outlet samples besides condensation. 


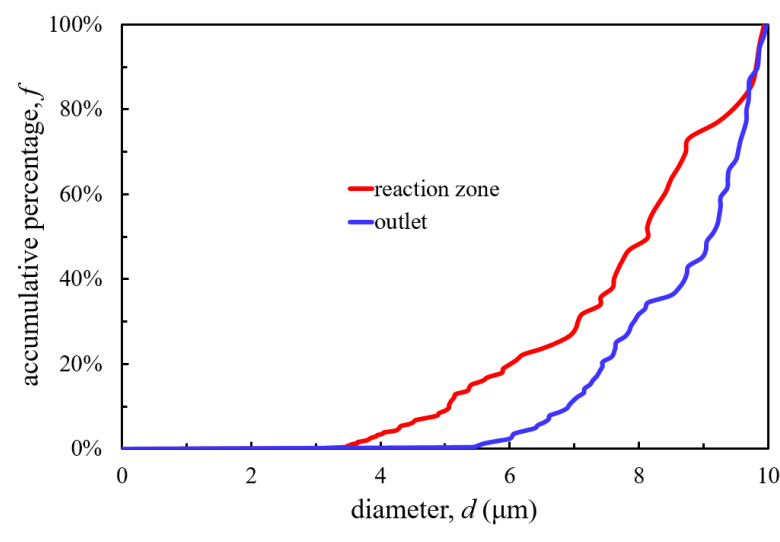

(a)

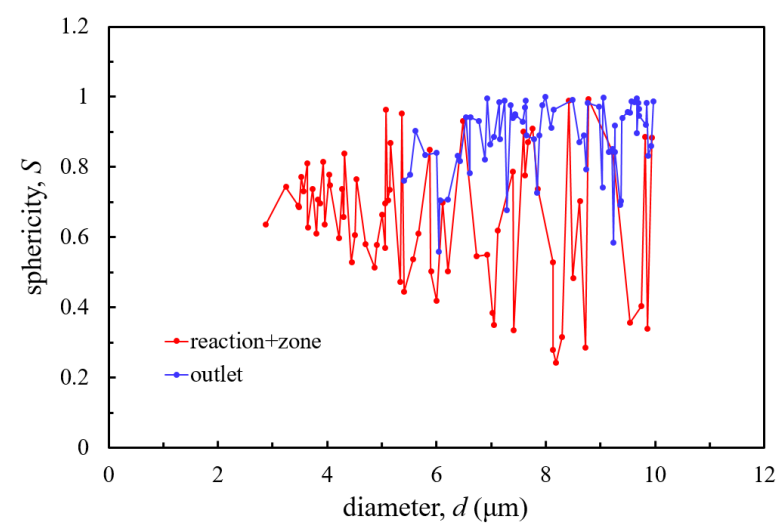

(b)

Figure 8. PM 10 properties, (a) diameter; (b) sphericity.

\subsection{Tar-Related Reaction Analysis}

For the gasification stage, the main reactions tar experienced include cracking, gasification, and soot forming, shown in Equations (1)-(3),

$$
\begin{gathered}
k_{\mathrm{TC}}=\rho Y_{\mathrm{tar}} A_{\mathrm{TC}} \exp \left(-E_{\mathrm{TC}} / R_{\mathrm{u}} T\right) \\
k_{\mathrm{TG}}=c_{\mathrm{tar}}{ }^{2.04} c_{\mathrm{h} 2 \mathrm{O}}{ }^{1.79}{ }^{79}{ }_{\mathrm{CO} 2}{ }^{0.95}{ }^{2}{ }_{\mathrm{CO}}{ }^{0.20}{ }^{2} c_{\mathrm{H} 2}{ }^{-0.74} A_{\mathrm{TG}} \exp \left(-E_{\mathrm{TG}} / R_{\mathrm{u}} T\right) \\
k_{\mathrm{SF}}=\rho Y_{\mathrm{tar}} A_{\mathrm{SF}} \exp \left(-E_{\mathrm{SF}} / R_{\mathrm{u}} T\right)
\end{gathered}
$$

where the kinetic parameters can be referred to the previous study [26]. Based on the measured gas composition, time scales for the tar cracking, gasification, and soot formation were calculated, compared to the gas flow time scale in the gasification channel, shown in Figure 9. Tar gasification is far slower than cracking and soot formation, causing no effect on tar behavior. Time scales of cracking and soot formation are close to each other, and smaller than flow time scale when temperature $>1100{ }^{\circ} \mathrm{C}$. According to the temperature field in Figure 6, tar cracking and soot formation take place near the reaction zone.

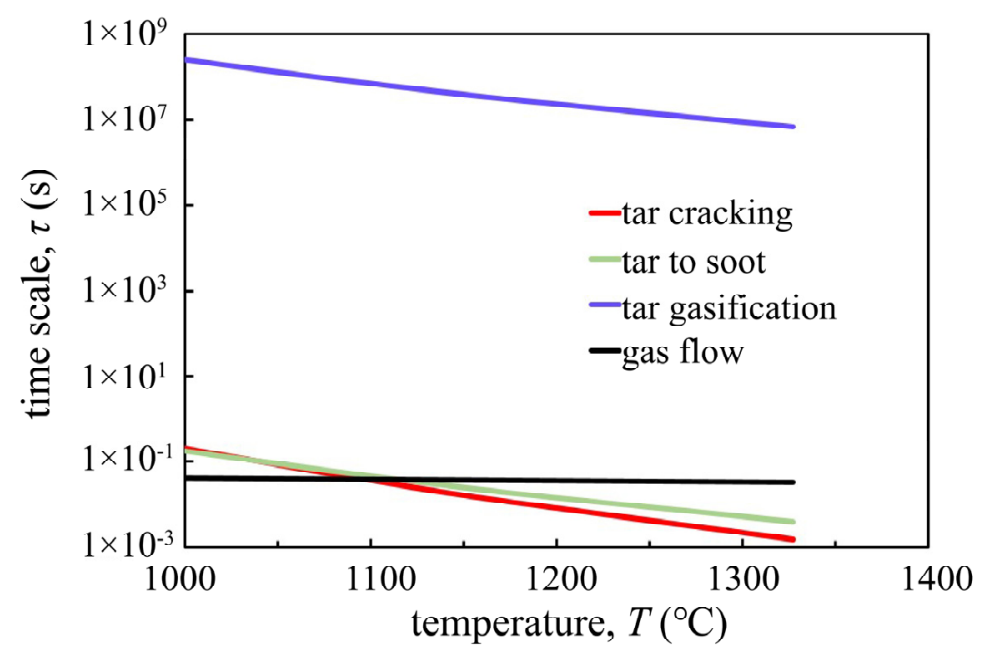

Figure 9. Time scale of tar-related reactions and gas flow.

\section{Discussion}

Underground coal gasification is a promising technology for mining of deep coal seams, while the potential pollution problems such as tar have drawn growing concern. In this work, an ex-situ underground coal gasification experimental system was built, which has a large reactor size compared to the gasified coal block. The heat loss leads to a pretty 
low outlet temperature, and thus the tar behavior at outlet is closer to field test compared to the lab tests in literature. The reported studies prior to now have only focused on the tar in the product gas, while the risk of condensed tar in the gasification channel has not been evaluated. The present work proposed a method for sampling and analyzing tar in the reaction zone, and making a detailed comparison with the tar at outlet. A sharp decrease of heavy tar content was found, and the mechanisms were discussed. Condensation due to a fast temperature drop is one of the main reasons for PAHs decreasing. Tar cracking and soot formation also cause the decrease of heavy tar, proven by the light gas and particulate matter results.

Different from the gasifier on the ground, the condensed tar in the underground gasifier is difficult to collect and deal with. It takes months, or even years, to detect the polluting effect on the underground water and soil. One can easily decrease the tar content in the product gas by decreasing the outlet temperature, while it does not mean that the pollution is controlled. Future underground gasification sites should not only monitor the tar in the product gas and the underground water, but also pay attention to the proportion of condensed tar remaining in the underground gasifier, establishing a comprehensive evaluation system. This might be realized by adding sampling equipment on the gas injector, since the heavy tar is formed mainly in the high temperature region near the gas inlet.

The present work has discussed the relationship between tar-related reactions and temperature. In fact, optimization of the temperature field is an ideal way to deal with the tar problem. The temperature in the oxidization region should not be too high in order to control the yields of heavy tar; while the temperature at the gasifier outlet should not be too low, thus the amount of condensed tar could be decreased. Staged oxygen supply is a promising method to meet such a requirement, which could apparently decrease the temperature gradient in the gasification channel. At the same time, the increase of temperature near the outlet leads to faster cracking of heavy tar, further reducing the potential for condensed tar.

The studies focused on the tar evolution mechanisms in underground coal gasification are rarely reported. It is suggested that more attention be paid to the life-cycle measurement and simulation of tar behaviors during the gasification process of coal seams, which is helpful for developing more techniques for pollution control and establishing an environmentally friendly technical system for underground coal gasification.

There are some limitations in this work. First, we have only two sampling points in the present work. In the future, tar samples from more different positions will be compared. Second, the experimental data is limited. More experiments need to be carried out, especially those focused on the relationship between temperature distribution and tar evolution. The research method proposed in the present work is useful for a comprehensive understanding of tar behaviors in underground gasification while more experiments are necessary in the future.

\section{Conclusions}

In this work, tar was sampled with our newly developed equipment from an ex-situ underground coal gasification experimental system and analyzed by GC-MS. The present work emphasized the differences of tar behaviors from the reaction zone and outlet, which are meaningful for comprehensive evaluation of the environmental issues of underground gasification. The tar evolution mechanisms and pollution-control methods are further discussed. The main conclusions are as follows:

1. Compared with the tar from reaction zone, the tar from outlet has a smaller percentage of high boiling point content, PAHs, C, O, N, S, Cl, Si, and a larger percentage of $\mathrm{H}$.

2. The PAHs percentage in tar at the outlet in this work is closer to the field data than the lab data from literature.

3. Condensation, tar cracking, and soot formation are the reasons for decrease of heavy tar from reaction zone to outlet. 
Author Contributions: Conceptualization, L.F.; Methodology, L.F.; Investigation, L.F.; Writingoriginal draft preparation, M.D.; Writing-review and editing, L.F.; Supervision, Y.W. and J.G.; Funding acquisition, L.F. All authors have read and agreed to the published version of the manuscript.

Funding: This research was funded by The National Natural Science Foundation of China, grant number 52106189; this research was also funded by Open Fund of the Key Laboratory of Deep Earth Science and Engineering, Ministry of Education (Sichuan University), grant number DESE 202110.

Institutional Review Board Statement: Not applicable.

Informed Consent Statement: Not applicable.

Data Availability Statement: The data presented in this study are available on request from the corresponding author. The data are not publicly available due to privacy.

Acknowledgments: The supervision of Qingliang Guan on tar reaction mechanisms is appreciated.

Conflicts of Interest: The authors declare no conflict of interest.

\section{References}

1. Zelenak, S.; Skvarekova, E.; Senova, A.; Wittenberger, G. The usage of UCG technology as alternative to reach low-carbon energy. Energies 2021, 14, 3718. [CrossRef]

2. An, N.; Zagorscak, R.; Thomas, H.R.; Gao, W. A numerical investigation into the environmental impact of underground coal gasification technology based on a coupled thermal-hydro-chemical model. Jounal Clean. Prod. 2021, 290, 125181. [CrossRef]

3. Mandapati, R.N.; Ghodke, P.K. Kinetic modeling of Indian lignites pyrolysis in the context of underground coal gasification (UCG). Fuel 2021, 283, 118939. [CrossRef]

4. Walowski, G. Gas Permeability Model for Porous Materials from Underground Coal Gasification Technology. Energies 2021, 14, 4462. [CrossRef]

5. Janoszek, T.; Masny, W. CFD Simulations of Allothermal Steam Gasification Process for Hydrogen Production. Energies 2021, 14, 1532. [CrossRef]

6. Perkins, G. Underground coal gasification-Part I: Field demonstrations and process performance. Prog. Energy Combust. Sci. 2018, 67, 158-187. [CrossRef]

7. Perkins, G. Underground coal gasification-Part II: Fundamental phenomena and modeling. Prog. Energy Combust. Sci. 2018, 67, 234-274. [CrossRef]

8. Strugała-Wilczek, A.; Stanczyk, K. Comparison of metal elution from cavern residue after underground coal gasification and from ash obtained during coal combustion. Fuel 2015, 158, 733-743. [CrossRef]

9. Strugała-Wilczek, A.; Stanczyk, K. Leaching behaviour of metals from post-underground coal gasification cavity residues in water differing in mineralization. Fuel 2016, 173, 106-114. [CrossRef]

10. Kumari, G.; Vairakannu, P. $\mathrm{CO}_{2}-\mathrm{O}_{2}$ dry reforming based underground coal gasification using low and high ash Indian coals. Fuel 2018, 216, 301-312. [CrossRef]

11. Kumari, G.; Vairakannu, P. Laboratory scale studies on $\mathrm{CO}_{2}$ oxy-fuel combustion in the context of underground coal gasification. J. $\mathrm{CO}_{2}$ Util. 2017, 21, 177-190. [CrossRef]

12. Xu, M.; Xin, L.; Liu, W.; Hu, X.; Cheng, W.; Li, C.; Wang, Z. Study on the physical properties of coal pyrolysis in underground coal gasification channel. Powder Technol. 2020, 376, 573-592. [CrossRef]

13. Mandal, R.; Maity, T.; Chaulya, S.K.; Prasad, G.M. Laboratory investigation on underground coal gasification technique with real-time analysis. Fuel 2020, 275, 117865. [CrossRef]

14. Pankiewicz-Sperka, M.; Stańczyk, K.; Płaza, G. Assessment of the chemical, microbiological and toxicological aspects of postprocessing water from underground coal gasification. Ecotoxicol. Environ. Saf. 2014, 108, 294-301. [CrossRef]

15. Zhou, L.; Zhang, J. Study On Green Safety Production Technology In Modern Coal Mines. Fresenius Environ. Bull. 2020, 29, 2850-2857.

16. Wiatowski, M.; Kapusta, K.; Stańczyk, K. Analysis and characteristics of tars collected during a pilot-scale underground coal gasification (UCG) trial. Fuel 2017, 208, 595-601. [CrossRef]

17. Wiatowski, M.; Kapusta, K.; Muzyka, R. Study of properties of tar obtained from underground coal gasification trials. Fuel 2018, 228, 206-214. [CrossRef]

18. Wiatowski, M.; Kapusta, K. Evolution of tar compounds in raw gas from a pilot-scale underground coal gasification (UCG) trial at Wieczorek mine in Poland. Fuel 2020, 276, 118070. [CrossRef]

19. Grabowski, J.; Korczak, K.; Tokarz, A. Aquatic risk assessment based on the results of research on mine waters as a part of a pilot underground coal gasification process. Process Saf. Environ. Prot. 2021, 148, 548-558. [CrossRef]

20. Mallett, C. Environmental controls for underground coal gasification. J. Power Energy 2018, 232, 47-55. [CrossRef]

21. Klebingat, S.; Kempka, T.; Schulten, M.; Azzama, R.; Fernández-Steegera, T.M. Innovative thermodynamic underground coal gasification model for coupled synthesis gas quality and tar production analyses. Fuel 2016, 183, 680-686. [CrossRef] 
22. Klebingat, S.; Kempka, T.; Schulten, M.; Azzama, R.; Fernández-Steegera, T.M. Optimization of synthesis gas heating values and tar by-product yield in underground coal gasification. Fuel 2018, 229, 248-261. [CrossRef]

23. Soukup, K.; Hejtmánek, V.; Čapek, P. Modeling of contaminant migration through porous media after underground coal gasification in shallow coal seam. Fuel Process. Technol. 2015, 140, 188-197. [CrossRef]

24. Liu, S.; Zhou, R.; Zeng, Y.; Zhao, J.; Hu, J.; Chen, F. Formation and characteristics of tar from underground coal gasification. J. China Univ. Min. Technol. 2013, 42, 271-277.

25. Wang, Z.; Cao, J.; Jiang, S.; Li, Y.; Liang, J. Characteristics of tar composition and content in Tianjin Jinghai underground coal gasification. Coal Eng. 2017, 49, 32-35.

26. Feng, L.; Wu, Y.; Xu, K.; Zhang, H.; Zhang, Y.; Zhang, M. Coal-Derived Soot Behaviors In O2/N2 And O2/Co2 Atmosphere Through 1-D Transient Coal Combustion Model. Energy Fuels 2019, 33, 3620-3629. [CrossRef] 